\title{
“You Make Them Do What?": A National Survey on Field Seminar Assignments
}

\section{Bruce Dalton}

\begin{abstract}
This national study of MSW field directors provides data on field seminars and assignments. Field directors at CSWE accredited or in-candidacy MSW programs were surveyed regarding program data, presence and nature of a field seminar, required assignments, and opinion questions about CSWE requirements. Findings from the 141 completed surveys (66.2\% response rate) show assignments are similar between foundation and concentration years, and also similar to assignments required in the BSW curriculum. This raises questions of curriculum redundancy and how to properly sequence field assignments. Other findings about field education and field seminar are also presented.
\end{abstract}

Keywords: Field seminar, field education

Field education has varied from the stepchild of the curriculum to the signature pedagogy. Field education programs vary from no field seminar to seminars of a variety of lengths and formats. Regarding traditional classroom courses, Shavelson states "instructors can introduce tremendous variation into seemingly standardized course formats" (1986, p. 52). The often unstructured nature of field seminars may allow for even greater variance in both quality and content. Field instructors also have varying degrees of training, experience, skill, and loyalty to the social work education program. Field seminars may be one place social work educators ensure that students in field placement are exposed to learning experiences seen as crucial by the program. However recent surveys show a significant minority of MSW programs (19\%) do not have field seminars and among those that do have seminars, 28\% report using all or mostly all adjuncts to lead them (Dalton, Stevens, \& Maas Brady, 2011). This creates opportunities for 'slippage' between the intentions of the program and the actuality of the seminar. There is currently little known about how field seminars are implemented in MSW programs in the U.S. The purpose of this research is to fill that gap by exploring how the field seminar is implemented. This study will investigate the type of field seminar assignments reported by MSW field directors and other aspects of field seminar delivery, such as length, frequency, texts, and format.

\section{LITERATURE REVIEW}

Social work field instruction has evolved from an apprenticeship model early in its history to an educationally-focused model in which experienced professionals are selected as field instructors to help students achieve the educational objectives of the field program (Bogo, 2005; Frumkin \& Lloyd, 1995). Field instruction is now seen as the signature pedagogy of social work by the Council on Social Work Education (CSWE, 2008). Shulman (2005) says that a signature pedagogy should be consistently applied and

Bruce Dalton, MSW, Ph.D., is an Associate Professor in the Department of Social Work at East Tennessee State University in Johnson City, TN.

Copyright (C) 2012 Advances in Social Work Vol. 13 No. 3 (Fall 2012), 618-632 
if a profession has a signature pedagogy "we should be able to find it replicated in nearly all the institutions that educate in those domains" (p. 54).

Signature pedagogy is defined as "the central form of instruction and learning in which a profession socializes its students to perform the role of practitioner" and its purpose is to "connect the theoretical and conceptual contribution of the classroom with the practical world of the practice setting" (EPAS, 2.3, CSWE, 2008). The connection between theory and practice is widely reported in the literature (e.g. Boisen \& Syers, 2004; Dalton, Stevens, \& Maas Brady, 2009; Henry, 2004; Homonoff, 2008; Noble, 2001). Boisen and Syers state "social work education rests on the assumption that competent social work practice is grounded in the intentional use of theory" (2004, p. 205). The field experience is where and when students connect the theoretical concepts learned in the classroom with the practical aspects of service provision while also gaining an appreciation for the breadth and depth of the many roles that a social worker performs. This approach is compatible with John Dewey's philosophy of progressive education in which students learn by doing (Scannell \& Simpson, 1996). Dewey believed having relevant experience in the wider world brought value and purpose to what happens in the classroom.

Although this perspective has long been accepted in social work education, it has also long been seen as difficult to implement; "However highly valued this integration of theory with practice may be, it is nevertheless hard to define” (Basch, 1942, p. 32). Bogo and Power (1992) found that 31\% of the 49 new field instructors surveyed believed teaching theory was unimportant. Reviewing five studies of student perception of field instruction, Bogo (2005) found that students do value reflective and conceptual learning activities that help to integrate theory and practice, yet only one of the five studies reviewed (Fortune, McCarthy, \& Abramson, 2001, as cited in Bogo) investigated whether the reported use of learning activities by field instructors that help integrate theory and practice were correlated to performance. Fortune found that neither making connections to theory nor making connections to classroom work were significantly related to performance as rated by the field instructor in an end of placement evaluation. Munson (1987) suggested that the direction of integration needs to be considered. The common assumption is that curriculum theory emanates from the classroom and spreads to field, but Munson suggests a better model may be to teach in the classroom what the students are exposed to in the field. Munson gives as an example an advanced practice track based on emotions encountered in the practice arena, such as anger, depression, anxiety, grief, etc.

The field seminar is seen as the setting in which the connection between theory and practice is made clear for the students (Mary \& Herse, 1992; Poe \& Hunter, 2009). It is in the seminar that students have the opportunity, and often the mandate, to make a conscious connection between classroom knowledge and theory, and the experience they are gaining in placement. The seminar may do this through informal or guided discussion as well as through more formal oral and written assignments. For example, this author has asked seminar students to come the next week with a specific behavioral example of a theory being used to direct a client intervention. The ensuing class discussion makes clear the different abilities of students to understand how theory is used in practice. A 
formal seminar assignment asking students to link theory and practice is congruent with the findings of Mary and Herse (1992), who found that student reports of theory/practice integration more often occurred in structured sessions than in unstructured ones.

The literature on assignments used in field seminars is shallow. Searching Social Work Abstracts on the terms "field seminar" $(\mathrm{n}=9)$, "field assignment(s)" $(\mathrm{n}=12)$, and "field placement” $(n=190)$ revealed few articles describing assignments specifically given in field seminar. The author found it common for articles to discuss assignments for field with no specification of whether it was for the field instructor to use alone or in conjunction with a field seminar leader, such as the process recording assignment that may be used by a field instructor with or without coordination with a field seminar (e.g., Black \& Feld, 2006; Canning \& Mullin, 2008; Hendricks, Finch, \& Franks, 2005; Knight, 2000). Fisher, Reed, Stough, and Matt (2007) describe a BSW senior field seminar that requires several two page mini-papers designed to integrate coursework with field experience. Potential topics include generalist opportunities in the agency and how the NASW Code of Ethics applies to field experiences. Noble (2001) reports on the use of a reflective workbook that students complete in a narrative form and then process in seminar or with field instructors with the purpose of linking theory and practice. Haslett (1997) reports on a two semester field assignment in which grant writing was taught in seminar and grants were then written by student groups to benefit a selected field placement. Poe and Hunter (2009) asked BSW field directors to identify which of 13 assignments were required as part of the field experience. The assignment most often required was a student-developed learning contract $(94.7 \%)$, followed by reflective writing, oral case presentation, written micro case analysis, process recording, social history, written macro activity analysis, environmental study, policy study, literature review on field population/experience, portfolio, eco-mapping, and lastly a written group case analysis (29.7\%). The top nine field assignments were required $50 \%$ or more of the time, and seven of those were written assignments. Poe and Hunter's data do not distinguish whether those assignments are a field seminar requirement or for another course. If many of these assignments are required in the field seminar, then the format may become more like a traditional classroom and less like a process group where field issues and student concerns are discussed. Shulman believes this process focus is important, stating "there are elements added through the group process that can have powerful and important impacts on a staff member that may not be present in individual supervision" (2010, p. 272). Poe and Hunter found that 57.7\% of seminar leaders report using content delivery often or very frequently, which may distract from the process focus of field seminar.

This present study will investigate the type of assignments from field seminars reported by MSW field directors and other aspects of field seminar delivery, such as length, frequency, textbooks, and format. This research is best characterized as exploratory and descriptive with the research question "What are the national patterns of MSW field seminar delivery?” The results will provide information about field seminar delivery that have not been previously reported. One hypothesis is suggested by the literature: in comparison to the BSW data collected by Poe and Hunter (2009), there will be a similar number and type of MSW field assignments. The new response categories in 
this research will show if those assignments are required in seminar or other classes. The implications of these results for the field seminar will be discussed.

\section{METHODOLOGY}

\section{Sample}

The sample population was the 219 CSWE accredited or in-candidacy MSW programs in the fall of 2009. The sample frame consisted of the 213 field directors (or MSW program director when a field director could not be identified) at CSWE accredited or in candidacy MSW programs for whom email addresses could be acquired. The sample frame was constructed by visiting the webpage of each accredited or in-candidacy program. In February 2010, 213 emails were sent out announcing the survey and providing a link to the survey site. Two reminder emails were sent out over the next several weeks. One hundred and forty-one surveys were completed for a response rate of $66.2 \%$.

\section{Survey}

The survey included program data, presence and nature of a field seminar, required field assignments, and opinion questions for the field director about CSWE requirements. The list of assignments was an amended list that Poe and Hunter (2009) used with BSW field directors. Three new items were added based on the literature and the author's experience and another item was added when one of Poe and Hunter's items was divided into two items (environmental study of the field agency and/or community became two separate items). The response categories were also changed to reflect whether the assignment was required in the seminar or elsewhere in the curriculum. Poe and Hunter had the response categories required, not required, and optional. This change was made because classes besides the field seminar may require assignments that are to be completed in the field. This is so common that Benjamin and Ward (2005) suggest students take all their course syllabi to their field instructor on the first day of field to begin coordination of course assignments required to be completed in field. This survey was piloted by sending it to ten field directors, six of whom completed it and provided feedback.

\section{RESULTS}

Of the 141 respondents, 130 were the field director, four were the MSW program director, two were field coordinators, 22 were seminar leaders, and 19 were liaisons. Several wrote in unique titles in addition to field related titles, such as clinical professor. Only two respondents provided no role. Most respondents were from public universities $(\mathrm{n}=101,72.7 \%)$. Field is graded pass/fail $63.1 \%$ of the time, A-F $29.8 \%$ of the time, and other $3.5 \%$ of the time. Respondents were asked to mark on a continuum, from $1=$ rural to $7=$ urban, the setting of their program. The results are shown in Table 1 . The mean was 5.1 showing most respondents considered their institution to be on the urban side of the continuum. 
Table 1: $\quad$ Rural/Urban Program Setting

\begin{tabular}{lrr}
\hline Rural/Urban & Frequency & Percent \\
\hline 1 Rural & 9 & 6.4 \\
2 & 8 & 5.7 \\
3 & 15 & 10.7 \\
4 & 25 & 17.9 \\
5 & 16 & 11.4 \\
6 & 16 & 11.4 \\
7 Urban & 51 & 36.4 \\
\hline Total & 140 & 100 \\
\hline
\end{tabular}

Respondents were asked how many MSW degrees were awarded by their program last year; the results are shown in Table 2. The median was in the 60-69 category (categories were collapsed for presentation in Table 2). The mean number of graduates each year was 106 (computed after the response categories were recoded to their midpoints and the 500+ category set to 500).

Table 2: $\quad$ Number of MSW Degrees Awarded By Program Last Year

\begin{tabular}{lrr}
\hline Number of MSW Degrees & Frequency & Percent \\
\hline $0-49$ & 52 & 37.7 \\
$50-99$ & 33 & 23.9 \\
$100-149$ & 20 & 14.5 \\
$150-299$ & 25 & 18.1 \\
$300-499$ & 7 & 5.1 \\
$500+$ & 1 & .7 \\
\hline Total & 138 & 100 \\
\hline
\end{tabular}

Chi-square was conducted to determine if programs were statistically more likely to require a field seminar in the foundation or concentration year. Though most programs report a field seminar at both levels, statistical significance was found, with more programs requiring field seminar in the foundation year (see Table 3). 
Table 3: $\quad$ Required Foundation and Concentration Seminars

\begin{tabular}{lcccr}
\hline & \multicolumn{4}{c}{ Concentration Seminar Required? } \\
& & Yes & No & Total (\%) \\
\hline Foundation Seminar & Yes & 79 & 26 & $105(76)$ \\
Required? & No & 7 & 26 & $33(24)$ \\
Total (\%) & & $86(62)$ & $52(38)$ & $138(100)$ \\
\hline & \multicolumn{4}{c}{$\mathrm{X}^{2}(1, \mathrm{~N}=138)=31.21, \mathrm{p}=.000$} \\
\hline
\end{tabular}

Statistical analysis revealed no significant relationship between either the rural/urban measure or whether the university was public or private and whether programs had either a foundation or concentration field seminar. There was a statistically significant relationship between the number of MSW degrees awarded each year and whether the program had a field seminar in either the foundation $(\mathrm{t}=-3.23, \mathrm{df}=136$, sig. $=.001)$ or concentration year $(\mathrm{t}=-5.5$, $\mathrm{df}=82$, sig. $=.000)$. Programs with a foundation seminar reported 90 MSW graduates per year and programs without a foundation seminar reported 152 MSW graduates per year. Programs with a concentration seminar reported 71 MSW graduates per year, and programs without a concentration seminar reported 162 MSW graduates per year.

Those with a field seminar report the seminar meets as shown in Table 4. At both the foundation and concentration levels, this variable was recoded to reflect the number of times the seminar meets in a 15 week semester and the 'other' category was replaced with a number when the respondent had entered a comment that provided that information. The length of the foundation seminars averaged 113 minutes and ranged from 45 minutes to three hours $(n=101)$. The length of each foundation semester was multiplied by the number of times it met per semester to compute the length of time spent in seminar each semester. This revealed the total amount of time in foundation seminar per semester ranged from 240 minutes to 2700 minutes with a mean of 1081.7 minutes (sd=543) and a median of 840. The length of the concentration seminars averaged 117 minutes and ranged from 45 minutes to eight hours $(n=81)$. The length of each concentration seminar was multiplied by the number of times it met per semester to compute the length of time spent in seminar each semester. This revealed the total amount of time spent in concentration seminar each semester ranged from 220 minutes to 2700 minutes with a mean of 988.2 minutes $(\mathrm{sd}=560)$ and a median of 840 . The total amount of time spent in concentration seminar was statistically different from the total amount of time spent in foundation seminar $(\mathrm{t}=2.08, \mathrm{df}=70$, sig=.031). So not only do fewer programs have a concentration seminar, when they do they do not spend as much time in seminar over the course of a semester. 
Table 4: $\quad$ Frequency of Foundation/Concentration Field Seminars

\begin{tabular}{lcc}
\hline & $\begin{array}{c}\text { Foundation } \\
\mathrm{n}(\%)\end{array}$ & $\begin{array}{c}\text { Concentration } \\
\mathrm{n}(\%)\end{array}$ \\
\hline Weekly & $43(41.3)$ & $31(37.3 \%)$ \\
Biweekly & $32(30.8)$ & $26(31.3)$ \\
Monthly & $15(14.4)$ & $15(18.1)$ \\
Other & $14(13.5)$ & $11(13.3)$ \\
\hline Total & 104 & 83 \\
\hline
\end{tabular}

Seminar textbooks were reported as required at 41 (39.8\%) of the 107 programs with a foundation field seminar. Thirty-one provided identifying information for their textbook(s). The most commonly used were The Social Work Practicum: A Guide and Workbook for Students (Garthwait, 2006) used by seven respondents, The Practicum Companion for Social Work: Integrating Class and Field Work (Birkenmaier \& BergWeger, 2007) used by 5 respondents, and The Successful Internship: Personal, Professional, and Civic Development (Sweitzer \& King, 2008) used by three respondents. Seminar textbooks were reported as required at 23 of the 86 programs $(27.4 \%)$ with a concentration field seminar. Fourteen provided identifying information for their textbook(s). Only one was used by two respondents, The Evidence-Based Internship: A Field Manual (Thomlison \& Corcoran, 2008).

Respondents identified whether all, some, or none of their field seminar was conducted online and what those components were (see Table 5). Significantly more of the concentration field seminars were in whole or part conducted online (Kendall's tau = .701 , sig. $<.001)$.

Table 5. $\quad$ Use of Online Medium for Field Seminar

\begin{tabular}{lrr}
\hline & Foundation & Concentration \\
\hline Is any of your field seminar conducted online? & 0 & $2(2.4 \%)$ \\
All & $25(23.8 \%)$ & $28(33.3 \%)$ \\
Some & $80(76.2 \%)$ & $54(64.3 \%)$ \\
None & 105 & 84 \\
Total & & 25 \\
Which components are at least in part completed online? & 21 & 23 \\
Discussion & 20 & 14 \\
Submitting assignments & 11 & 4 \\
Accessing readings & 5 & 5 \\
Viewing videos & 7 & 25 \\
Other & & \\
\hline
\end{tabular}


Field directors were asked which assignments were required in the field or elsewhere in the curriculum; the results are presented in Tables 6 and 7. For the foundation year the response pattern was overall very similar to the BSW responses reported in Poe and Hunter (2009). The three most common items were the same in both. The next two items in the foundation data were new, but the next two (process recording and written micro case analysis/study) were fifth and fourth in Poe and Hunter's data. A visual examination of the data also reveals similarity between the foundation and concentration years with only a few in different rank order (in Table 7 the items are listed in the same order as in Table 6 for ease of comparison).

Table 6: $\quad$ Assignments Required in Foundation Year

\begin{tabular}{lcc}
\hline Foundation Year Assignment & $\begin{array}{c}\text { In Foundation } \\
\text { Seminar } \\
\text { ( } \%)\end{array}$ & $\begin{array}{c}\text { Elsewhere in Foundation } \\
\text { Curriculum } \\
\text { n (\%) }\end{array}$ \\
\hline Student developed learning contract & $88(82.2)^{*}$ & $16(15.0)$ \\
Reflective writing on the field experience & $85(79.4)$ & $12(11.2)$ \\
Oral case presentation & $67(62.6)$ & $27(25.2)$ \\
Oral presentation of the placement agency & $67(62.6)$ & $17(15.9)$ \\
Required readings & $53(49.5)$ & --- \\
Process recording & $47(43.9)$ & $20(18.7)$ \\
Written micro case analysis/study & $45(42.1)$ & $39(36.4)$ \\
Environmental study of the field agency & $42(39.3)$ & $24(22.4)$ \\
Written macro activity analysis/study & $33(30.8)$ & $44(41.1)$ \\
Social history & $22(20.6)$ & $42(39.3)$ \\
Eco-mapping & $19(17.8)$ & $40(37.4)$ \\
Written group case analysis/study & $19(17.8)$ & $34(31.8)$ \\
Policy study from field experience & $18(16.8)$ & $44(41.1)$ \\
Portfolio & $16(15.0)$ & $15(14.0)$ \\
Environmental study of the community & $14(13.1)$ & $39(36.4)$ \\
Literature review on the field placement setting & $11(10.3)$ & $20(18.7)$ \\
Literature review on the field placement population & $10(09.3)$ & $22.4)$ \\
\hline * Percentages are of the 107 with a foundation field seminar. & & \\
\hline
\end{tabular}

What can also be seen from both tables is that some assignments are seen as more appropriate for field seminar and some are seen as more appropriate for elsewhere in the curriculum. When comparing the percentage of assignments required in seminar in the foundation and concentration years, the greatest difference was 10.5\% (literature review on the field placement population). When comparing the percentage of these assignments required elsewhere in the foundation and concentration years, the greatest difference was 
8.3\% (eco-mapping). Most differences were much lower. This visual inspection of the data reveals the pattern of assignments given to both foundation and concentration years in the field seminar and elsewhere in the curriculum was remarkably similar.

Table 7: $\quad$ Assignments Required in Concentration Year

\begin{tabular}{lcc}
\hline Concentration Year Assignment & $\begin{array}{c}\text { In Concentration } \\
\text { Seminar } \\
\text { n (\%) }\end{array}$ & $\begin{array}{c}\text { Elsewhere in } \\
\text { Concentration Curriculum } \\
\text { n (\%) }\end{array}$ \\
\hline Student developed learning contract & $76(88.4)^{*}$ & $8(09.3)$ \\
Reflective writing on the field experience & $64(74.4)$ & $10(11.6)$ \\
Oral case presentation & $58(67.4)$ & $17(19.8)$ \\
Oral presentation of the placement agency & $49(57.0)$ & $15(17.4)$ \\
Required readings & $41(47.7)$ & --- \\
Process recording & $37(43.0)$ & $14(16.3)$ \\
Written micro case analysis/study & $41(47.7)$ & $25(29.1)$ \\
Environmental study of the field agency & $25(29.1)$ & $19(22.1)$ \\
Written macro activity analysis/study & $27(31.4)$ & $34(39.5)$ \\
Social history & $18(20.9)$ & $30(34.9)$ \\
Eco-mapping & $13(15.1)$ & $25(29.1)$ \\
Written group case analysis/study & $18(20.9)$ & $29(33.7)$ \\
Policy study from field experience & $22(25.6)$ & $30(34.9)$ \\
Portfolio & $21(24.4)$ & $13(15.1)$ \\
Environmental study of the community & $13(15.1)$ & $27(31.4)$ \\
Literature review on the field placement setting & $11(12.8)$ & $18(20.9)$ \\
Literature review on the field placement population & $17(19.8)$ & $24.4)$ \\
\hline * Percentages are of the 86 with a concentration field seminar. & & \begin{tabular}{c}
$17)$ \\
\hline
\end{tabular} \\
\hline
\end{tabular}

Respondents were asked what other assignments are required for their foundation or concentration seminars that were not on the list to choose from. Twenty six respondents added 27 foundation assignments and 17 respondents added 18 concentration assignments. Of these only one assignment was mentioned as many as three times, a capstone assignment. This indicates there were no significant omissions in the list of assignments on the survey.

As discussed above nearly all responding programs require written assignments in both field seminars, and most require multiple written seminar assignments. This may cause the seminar to take on a didactic nature as students require information to complete written assignments. Even if the information necessary to complete the assignment is largely presented in another course, the seminar leader may be called upon to explain the assignment. Respondents were asked to rate their seminar on a continuum from 1 to 7 , 
with one being a process format and seven being a lecture format. The results in Table 8 show that most fall on the process end of the continuum with no significant difference between foundation and concentration year.

Table 8. Foundation/Concentration Seminars Rated on Process/Lecture Continuum.

\begin{tabular}{lrr}
\hline & Foundation Seminar & Concentration Seminar \\
\hline 1 Process & $28(26.9 \%)$ & $17(21 \%)$ \\
2 & $35(33.7)$ & $35(43.2)$ \\
3 & $23(22.1)$ & $13(16)$ \\
4 & $16(15.4)$ & $16(19.8)$ \\
5 & $1(1)$ & 0 \\
6 & $1(1)$ & 0 \\
7 Lecture & 0 & 0 \\
Total & 104 & 81 \\
\hline
\end{tabular}

Respondents were asked if seminar should be required by CSWE. For the foundation year $78.4 \%$ replied yes and for the concentration year $62.5 \%$ replied yes, a significant difference $\left(\mathrm{X}^{2}=38.363, \mathrm{df}=1, \mathrm{p}<.001\right)$. In the foundation year 12 respondents who did not have a field seminar believed it should be required, while 9 respondents who did have a field seminar believed it should not be required. In the concentration year the numbers were 14 and 13, respectively.

Respondents were asked if there were certain field seminar assignments that should be required of all CSWE accredited programs. For the foundation year 64 (48.1\%) replied yes and for the concentration year $52(39.4 \%)$ replied yes, a significant difference $\left(\mathrm{X}^{2}=\right.$ 62.303, $\mathrm{df}=1, \mathrm{p}<.001)$. Respondents were asked what field seminar assignments they believed should be required. Fifty-five respondents mentioned 32 foundation field seminar assignments, and 47 respondents mentioned 39 concentration field seminar assignments. The most commonly noted were also those that were ranked high on Tables One and Two as being currently assigned. For the foundation year those were Process Recordings ( $\mathrm{n}=20)$, Reflection Assignments (16), Case Presentations (15), and Learning Contracts (15). For the concentration year those were Case Presentations (16), Process Recordings (16), Reflection Assignments (11), and Learning Contracts (10).

Respondents were asked if there was anything else that they could tell us to help us understand the field seminar at their program; comments were provided by 65 respondents. Using the method described by Kerlinger (1986) a content analysis was conducted to identify themes in the comments. The most mentioned theme was the importance of the seminar function of integrating theory and practice $(n=10)$. Six respondents without seminars reported that discussion of field issues was expected in one or more practice classes, though two expressed dissatisfaction with this arrangement. One 
respondent said their program was adding field seminar and another said they were dropping it. Respondents were also asked if there was anything else they could tell us to better understand field issues in general and comments were provided by 37 respondents. No common themes emerged from these comments. Some comments were suggestions, some were about their own programs, some were emotive, and some were questions. One respondent wrote "We are attempting to become less of a step child to course curriculum. Any suggestions?” Sorry, no.

\section{Limitations}

This study was limited by several factors. Respondents were mostly field directors who may not know all the details of the overall curriculum and whether assignments from other courses are linked to field, though over time they would likely become familiar with most or all of them. To more accurately measure field assignments required by other courses would require reviewing all course syllabi or surveying all faculty, a much bigger task than surveying field directors.

Another limitation of the study is its use of assignment titles and not the full assignment description. Completing many of the assignments listed in Tables 6 and 7 may allow or require discussion of the connection of theory and practice, but it is also possible the assignment instructions for a particular course or seminar could be written in such a way that it could be completed without explicitly connecting theory and practice.

\section{DISCUSSION}

The purpose of this research was to explore currently unknown aspects of field seminar with an emphasis on required assignments. That purpose has been met as a picture was drawn of field seminar characteristics that is informative to field directors as they implement their field component, as well as faculty who teach classroom courses that support field.

Fewer respondents reported a field seminar in the concentration year than the foundation year. Further, when programs have concentration year seminar they meet 93 minutes less over the course of a semester than foundation seminar. The author is aware of no literature claiming seminar is more helpful in one or the other year. When the percentage of MSW programs with a field seminar was previously reported, no distinction was made between foundation and concentration years, so this is a new finding. One variable that was found to impact whether a program had a seminar either year was the number of MSW graduates, with larger programs less likely to have a seminar. It may be that larger programs have fewer financial resources per student and can't afford a seminar, that larger programs are more research-oriented and take less time for student contact through a field seminar, find it hard to coordinate a large number of seminars, or some other reason. Future research could examine the cause of this difference.

The textbooks and assignments required may indicate a difference in purpose between foundation and concentration seminars. More foundation seminars than concentration seminars require textbooks. Requiring a textbook suggests foundation 
seminar is seen as more basic and informational and implies a more traditional educational process. However the data in Table 8 shows respondents more likely to claim a process than a lecture method for both seminar levels. Shulman (2010) states the dynamic and process focused group is a valuable educational opportunity that may contribute to skill as a future group worker and social worker. If textbooks and assignments do create a traditional classroom environment in seminar then this educational opportunity will be missed.

A visual examination of the assignments required of foundation and concentration students reveal them to be very similar. Further, a visual examination shows that the assignments required of foundation and concentration students are similar to those required of BSW students in the Poe and Hunter study (2009). It is possible that some different use is being made of the assignments in the different levels, but these data cannot determine that. Foundation students should be focused on skill development and the generalist model, while concentration year students should be making use of theorybased interventions and making conceptual connections between theory and practice (Boisen \& Syers, 2004). However the patterns found in this data suggest that there is little deliberate use of assignments for different curriculum levels such as those proposed by Fisher and colleagues (2007) or Noble (2001). Unfortunately concentration seminar assignments may often be a case of more of the same. Curriculum redundancy has previously been identified as a problem elsewhere in the social work curriculum (Dalton \& Wright, 2003, 2004), so it would not be surprising if it were also the case in field.

Most respondents believe seminar should be required by CSWE, especially for foundation year. This position is in accord with Shulman (2005) that a signature pedagogy should be consistently applied. It is difficult to imagine that field is consistently applied when programs can choose whether to have a seminar. This author has taught in programs with and without a seminar, and has seen learning take place in seminar that was not possible in any other setting because of the seminar's process focus and focus on field.

Some assignments required by courses other than the field seminar are expected to be completed in field or draw upon field experience. This requires coordination between field and other courses. If assignments from seminar or any class are expected to be completed in field, then the field instructor needs to know this as early as possible so that planning for those activities can take place. In the author's seminar students are required to have their field instructor sign the assignment page of all their syllabi and put copies in their field portfolio by the third week of class. This ensures students and their field instructors have discussed required assignments early in the semester as suggested by Benjamin and Ward (2005).

\section{CONCLUSION}

This study has indicated that the field placement and seminar is unevenly implemented by CSWE accredited MSW programs. However EPAS (CSWE, 2008) indicates there are different ways to get to the same end point, so if a field program achieves the goal of teaching students theory guided practice, then the specifics of their 
field program can be left up to them. CSWE does have certain requirements for field (e.g., minimum number of field hours, field instructor training), suggesting that some things are seen as necessary to meet professional educational competencies. It is unclear why some requirements exist while other aspects of field education, such as a seminar, do not. Requiring a field seminar would address the recommendations of Wayne, Bogo, and Raskin (2010) that field education have more student-to-student accountability and greater student visibility of their field education performance, thus continuing our movement away from the one-to-one supervisory model associated with psychodynamic theory. A required field seminar would also replicate our signature pedagogy across the field as recommended by Shulman (2005). In the absence of a field seminar it becomes incumbent on the program to demonstrate it is otherwise meeting the primary goal of field seminar, that of integrating theory and practice. A future study could investigate how MSW programs with and without seminar integrate theory and practice in their field component.

Most of the assignments required in field seminar (Tables 6 and 7) seem to lend themselves to the measurement of many EPAS competencies and practice behaviors. It would be tempting for any program to measure student attainment of competencies with these assignments in a field seminar, and the author's program and surely many others do so. There is however little guidance in the literature for choosing field assignments and less that empirically tests their effectiveness in meeting or measuring specific competencies. There is no research on why specific field assignments are chosen, though it is likely they are chosen based on each program or educator's teaching experience and tradition. A next step would be to empirically link specific field assignments to specific competencies at the foundation and concentration levels. This would raise social work education to the level of evidence-based practice and model this process for our students.

\section{References}

Basch, G. (1942). Class room and field work: Their joint contribution to skill. In V. P. Robinson (Ed.), Training for skill in social case work (pp. 32-54). Philadelphia: University of Pennsylvania Press.

Benjamin, S., \& Ward, J. (2005). Ten tips for integrating the classroom and fieldwork. The New Social Worker, 12(1), 6-7.

Birkenmaier, J., \& Berg-Weger, M. (2007). The practicum companion for social work: Integrating class and field work ( $2^{\text {nd }}$ ed.). Boston: Allyn and Bacon.

Black, P., \& Feld, A. (2006). Process recording revisited: A learning-oriented thematic approach integrating field education and classroom curriculum. Journal of Teaching in Social Work, 26(3/4), 137-153.

Boisen, L., \& Syers, M. (2004). The integrative case analysis model for linking theory and practice. Journal of Social Work Education, 40(2), 205-217.

Bogo, M. (2005). Field instruction in social work: A review of the research literature. The Clinical Supervisor, 24(1/2), 163-193. 
Bogo, M., \& Power, R. (1992). New field instructors' perceptions of institutional supports for their roles. Journal of Social Work Education, 28(2), 178-189.

Canning, J., \& Mullin, W. (2008). Student process recording in practice with children. The Clinical Supervisor, 27(1), 61-75.

Council on Social Work Education. (2008). Educational policy and accreditation standards. Alexandria, VA: Author. Available online at http://www.cswe.org/CSWE/

Dalton, B., Stevens, L., \& Maas-Brady, J. (2009). Surveying the BSW field director. Journal of Baccalaureate Social Work, 14(2), 17-29.

Dalton, B., Stevens, L., \& Maas-Brady, J. (2011). “How do you do it?”: MSW Field Director Survey. Advances in Social Work, 12(2), 276-288.

Dalton, B., \& Wright, L. (2003). Exploring redundancy in social work education. Advances in Social Work, 4(1), 48-63.

Dalton, B., \& Wright, L. (2004). Eliciting student perceptions regarding curriculum redundancy. Journal of Teaching in Social Work, 24(1), 55-72.

Fisher, L., Reed, N., Stough, L., \& Matt, T. (2007). Making the most of field seminar. The New Social Worker, 14(4), 8-10.

Frumkin, M., \& Lloyd, G. A. (1995). Social work education. In R. L. Edwards (Ed.-inChief), Encyclopedia of social work (19 ${ }^{\text {th }}$ ed., Vol. 3, pp. 2238-2247). Washington, DC: NASW Press.

Garthwait, C. (2009). The social work practicum: A guide and workbook for students (4 $4^{\text {th }}$ ed.). Boston: Allyn and Bacon.

Haslett, D. (1997). The education task group: Teaching proposal writing to social work students. Social Work with Groups, 20(4), 55-67.

Hendricks, C., Finch, J., \& Franks, C. (2005). Learning to teach, teaching to learn: A guide for social work field education. Alexandria, VA: CSWE Press.

Henry, P. (2004). The role of field instruction in social work education. The New Social Worker, 11(4), 7-9.

Homonoff, E. (2008). The heart of social work: Best practitioners rise to challenges in field instruction. The Clinical Supervisor, 27(2), 135-168.

Kerlinger, F. (1986). Foundations of behavioral research ( $3^{\text {rd }}$ ed.). New York: Holt, Rinehart, and Winston.

Knight, C. (2000). Engaging the student in the field instruction relationship: BSW and MSW students' views. Journal of Teaching in Social Work, 20(3/4), 173-201.

Mary, N., \& Herse, M. (1992). What do field seminars accomplish? Student and instructor perspectives. Journal of Teaching in Social Work, 6(2), 59-73.

Munson, C. (1987). Field instruction in social work. Journal of Teaching in Social Work, 1(1), 91-109. 
Noble, C. (2001). Researching field practice in social work education. Journal of Social Work, 1(3), 347-360.

Poe, N., \& Hunter, C. (2009). A curious curriculum component: The nonmandated "given” of field seminar. Journal of Baccalaureate Social Work, 14(2), 31-47.

Scannell, J. J., \& Simpson, K. (1996). Shaping the college experience outside the classroom. Rochester, NY: University of Rochester.

Shavelson, R. J. (1986). Evaluating Student Outcomes from Telecourse Instruction: A Feasibility Study (Report No. ISBN-0-8330-0746-7; RAND/R-3422-DPB). Santa Monica, CA: Rand Corporation. (ERIC Document Reproduction Service No. ED 311 867)

Shulman, L. S. (2005). Signature pedagogies in the professions. Daedalus, 134(3), 52-59.

Shulman, L. (2010). Interactional supervision ( $3^{\text {rd }}$ ed.). Washington, DC: NASW Press.

Sweitzer, H., \& King, M. (2008). The Successful internship: Personal, professional, and civic development ( $3^{\text {rd }}$ ed.). Belmont, CA: Brooks/Cole.

Thomlison, B., \& Corcoran, K. (2008). The evidence-based internship: A field manual. New York: Oxford University Press.

Wayne, J., Bogo, M., \& Raskin, M. (2010). Field education as the signature pedagogy of social work education. Journal of Social Work Education, 46(3), 327-339.

\section{Author note:}

Address correspondence to: Bruce Dalton, Department of Social Work, Box 70645, East Tennessee State University, Johnson City, TN 37614-1702. Email: dalton@etsu.edu 